\title{
Lisina digestível e zinco quelado para frangos de corte machos: desempenho e retenção de nitrogênio na fase pré-inicial ${ }^{1}$
}

\section{Lilian Bernadete Namazu², Estela Kobashigawa², Ricardo Albuquerque ${ }^{3}$, Eliana Aparecida Schammass ${ }^{4}$, Paula Takeara ${ }^{5}$, Messias Alves da Trindade Neto ${ }^{3}$}

\author{
1 Projeto financiado pela FUNDAG, Campinas, SP. \\ 2 Mestranda do Departamento de Nutrição e Produção Animal-VNP- FMVZ-USP. \\ 3 Departamento de Nutrição e Produção Animal-VNP-USP-FMVZ, Avenida Duque de Caxias Norte, 225, Pirassununga, São Paulo, Brasil, \\ CEP: $13635-900$. \\ 4 Instituto de Zootecnia - Rua Heitor Penteado 56, Nova Odessa, SP, CEP: 13460-000 \\ ${ }^{5}$ Mestre em Nutrição Animal
}

\begin{abstract}
RESUMO - Em dois ensaios experimentais, avaliaram-se níveis de lisina digestível (0,90; 1,00; 1,10; 1,20 e 1,40\%) combinados a zinco quelado (43 e $253 \mathrm{ppm}$ ) para frangos de corte machos. Os períodos considerados foram: 1 a 11 dias de idade (desempenho) e 1 a 7 dias de idade (balanço de nitrogênio). O delineamento experimental utilizado foi de blocos ao acaso, em esquema fatorial $5 \times 2$. No ensaio de desempenho, utilizaram-se 7 repetições e 15 aves por unidade experimental e, no ensaio de digestibilidade, 6 repetições e 6 aves por unidade experimental. As dietas continham 2.960 de EM/kg e 21\% de proteína bruta. Na fase de 1 a 11 dias de idade, não houve efeito de interação lisina digestível $\times$ zinco quelado no desempenho, mas verificou-se efeito quadrático dos níveis de lisina digestível sobre o peso final, o ganho de peso e o ganho de peso relativo e efeito linear crescente no consumo de ração. A conversão alimentar não diferiu com as variações dos níveis de lisina digestível e zinco na dieta. Nas condições de avaliação do desempenho, o nível ótimo de lisina digestível para frangos de corte machos mantidos em piso de concreto é de 1,19\%. Na fase de 1 a 7 dias de idade, não houve influência da relação entre níveis de lisina digestível e zinco quelado no balanço de nitrogênio. A retenção de nitrogênio aumentou de forma linear crescente com o aumento da concentração de lisina digestível na dieta, o que está de acordo com o aumento linear do ganho de peso e da eficiência alimentar. A exigência de lisina digestível para frangos de corte machos de 1 a 7 dias de idade é igual ou superior a 1,40\%.
\end{abstract}

Palavras-chave: aminoácidos, deposição de nutrientes, micronutrientes, nutrição

\section{Digestible lysine and zinc chelate to male broiler: Performance in the pre- initial phase and nitrogen retention}

\begin{abstract}
Two experiments were carried out to evaluate different levels of digestible lysine $(0.90 ; 1.00 ; 1.10 ; 1.20$; e $1.40 \%$ ) combined with zinc chelate (43 and $253 \mathrm{ppm}$ ) to male broiler. The considered periods were: initial phase - performance ( 1 to 11 days old) and nitrogen retention (1 to 7 days old). A randomized block experimental design in a $5 \times 2$ factorial arrangement was used. In performance assay, 7 replications and 15 birds per experimental unit was used. In the digestibility essay, 6 replications 6 birds for experimental unit were used. The diets contained $2.960 \mathrm{kcal} / \mathrm{kg} \mathrm{ME}$ and $21.0 \%$ crude protein. In the initial phase, there was no digestible lysine $\times$ zinc chelate interaction on performance study, however a quadratic effect of digestible lysine on final weight, weight gain, relative weight gain and crescent linear effect in feed intake was observed. In feed: gain ratio did not differ with digestible lysine level and zinc chelate in the diet. In the performance, the better digestible lysine level for broiler raised in concrete floor is $1.19 \%$. From 1 at 7 days old, there was no influence of the combinations of digestible lysine and zinc chelate on nitrogen balance. The nitrogen retention linearly increased as digestible lysine increased in the diet. This response coincided with linear increase of weight gain and feed: gain ratio. A digestible lysine requirement for male broilers from 1 to 7 days old is equal or bigger then $1.40 \%$ for male broiler from one at seven days of age.
\end{abstract}

Key Words: amino acids, micronutrientes, nutrient depositions, nutrition

\section{Introdução}

A atualização das exigências nutricionais na formulação das rações é necessária, em virtude do contínuo melho- ramento genético das aves, que altera a produtividade e a demanda nutricional de mantença das linhagens das aves, assim como a velocidade de crescimento, que pode variar com o sexo e a conformação dos frangos (cortes ou carcaças). 
Essa diferenciação provoca mudança nas demandas por aminoácidos (Kidd, 2001). A exigência dos aminoácidos pode ser estimada a partir da lisina, aminoácido padrão na relação com os demais, por ser esse priorizado para formação protéica (Baker \& Han, 1994).

A demanda nutricional é maior nas fases iniciais de crescimento. Nos mesmos períodos, a eficiência de utilização dos aminoácidos se associa ao aumento da massa muscular e/ou da retenção de nitrogênio. Segundo Baker \& Han (1994), essa nutrição protéica é fundamental no desempenho de frangos de corte e a lisina, referência entre os aminoácidos, se destina à deposição protéica. Nas rações para frangos corte, o correto fornecimento desse aminoácido promove melhora significativa na conversão alimentar e no rendimento de peito (Azcona et al., 2003).

Zinco é um mineral traço essencial ao metabolismo de proteína, carboidrato e gordura e está relacionado à atividade de 300 enzimas do corpo. É fundamental na divisão celular e na síntese de DNA e proteína, portanto, está associado ao crescimento de tecidos e às funções do sistema imune, à produção de prostaglandina e à mineralização óssea, entre outras funções (Cheng et al., 1998). A essencialidade biológica do zinco está relacionada a mecanismos homeostáticos, que regulam a absorção e captação celular, à distribuição pelos compartimentos intracelulares e pelas macromoléculas, além de sua excreção (Ferreira et al., 2002).

Os minerais quelatados podem substituir as fontes inorgânicas em níveis mais baixos, no quais o desempenho é mantido ou melhorado (Spears et al., 1992), e ainda reduzem a poluição ambiental (Lee et al., 2001). O zinco orgânico é importante na participação da estrutura de aproximadamente 160 enzimas (metaloenzimas) em diferentes espécies animais e beneficia o desempenho de frangos de corte (Kidd \& Ker,1996). Fallavena (2000) concluiu que a adição de complexo de zinco melhora a cicatrização, aumenta a resistência da pele e melhora o empenamento, além de promover benefícios indiretos no estado de saúde da ave. Hudson et al. (2005) constataram que dietas para frangos de corte suplementadas com zinco e aminoácidos (ZnAA) favorecem o crescimento e a conversão alimentar das aves de 0 a 17 dias de idade, sugerindo que níveis mais baixos do mineral favorecem a absorção do aminoácido.

Aoyagi \& Bakos (1993), avaliando a concentração de zinco nos ossos, verificaram que o valor biológico do zinco quelado zinco-lisina para aves é de $111 \%$ em comparação ao sulfato de zinco (100\%).

Objetivou-se neste estudo determinar o melhor nível de lisina digestível associado ao zinco quelado para frangos de corte machos e seus efeitos no desempenho ( 1 aos 11 dias de idade) e na retenção de nitrogênio (1 a 7 dias de idade).

\section{Material e Métodos}

O estudo foi conduzido no período de 19 a 30 de setembro de 2005 no Aviário Experimental do Departamento de Nutrição e Produção Animal da Faculdade de Medicina Veterinária e Zootecnia da Universidade de São Paulo, Campus de Pirassununga, São Paulo. O clima da região é do tipo subtropical, com inverno seco e verão quente e chuvoso.

No experimento 1, foram utilizados 1.050 pintinhos de 1 dia de idade, da linhagem Ross, machos, com peso médio inicial de $46 \mathrm{~g}$. As aves foram instaladas em galpão de alvenaria dividido em 35 boxes de $4,25 \mathrm{~m}^{2}$. Os boxes foram subdivididos para obtenção de 70 unidades experimentais, equipados com lâmpada infravermelha e forrados com cama de maralhava para aquecimento dos pintinhos. Desde o primeiro dia, os pintinhos receberam as dietas experimentais e água à vontade. No início e ao final do ensaio (11 dias de idade), as aves e as sobras de ração foram pesadas para cálculo das médias de ganho de peso, consumo de ração e conversão alimentar, considerando o ganho de peso corrigido pela mortalidade.

No experimento 2, foram utilizados 360 pintinhos de 1 dia de idade, linhagem Ross, machos, com peso médio inicial de $46 \mathrm{~g}$. Os pintos foram criados até 7 dias de idade em baterias de aço galvanizado para estudo de digestibilidade da matéria seca (MS) e do balanço do nitrogênio. Adotou-se o método de coleta total de excretas (Farrell, 1978), de modo que os três primeiros dias foram de adaptação às rações experimentais e do $4^{0}$ ao $7 \stackrel{0}{ }$ dia, o período de coleta. A coleta foi realizada uma vez ao dia, pela manhã, estabelecendo-se intervalo de 24 horas. O material coletado foi acondicionado em sacos plásticos, identificados de acordo com o nível de zinco e a repetição, e congelado a menos $18^{\circ} \mathrm{C}$ para posteriores análises.

As amostras de fezes foram colocadas em estufa ventilada a $65^{\circ} \mathrm{C}$, durante 48 horas, para obtenção da amostra seca ao ar. Depois de seca, cada amostra foi pesada, moída e acondicionada em sacos plásticos até o procedimento da análise.

Do primeiro ao sétimo dia de vida, foi avaliado o consumo de ração e, do quarto ao sétimo dia, foram coletadas amostras das excretas para determinação do balanço de nitrogênio.

O delineamento experimental utilizado em ambos os experimentos foi o inteiramente casualizado, em esquema 
Tabela 1 - Composição das dietas experimentais fornecidas na fase pré-inicial

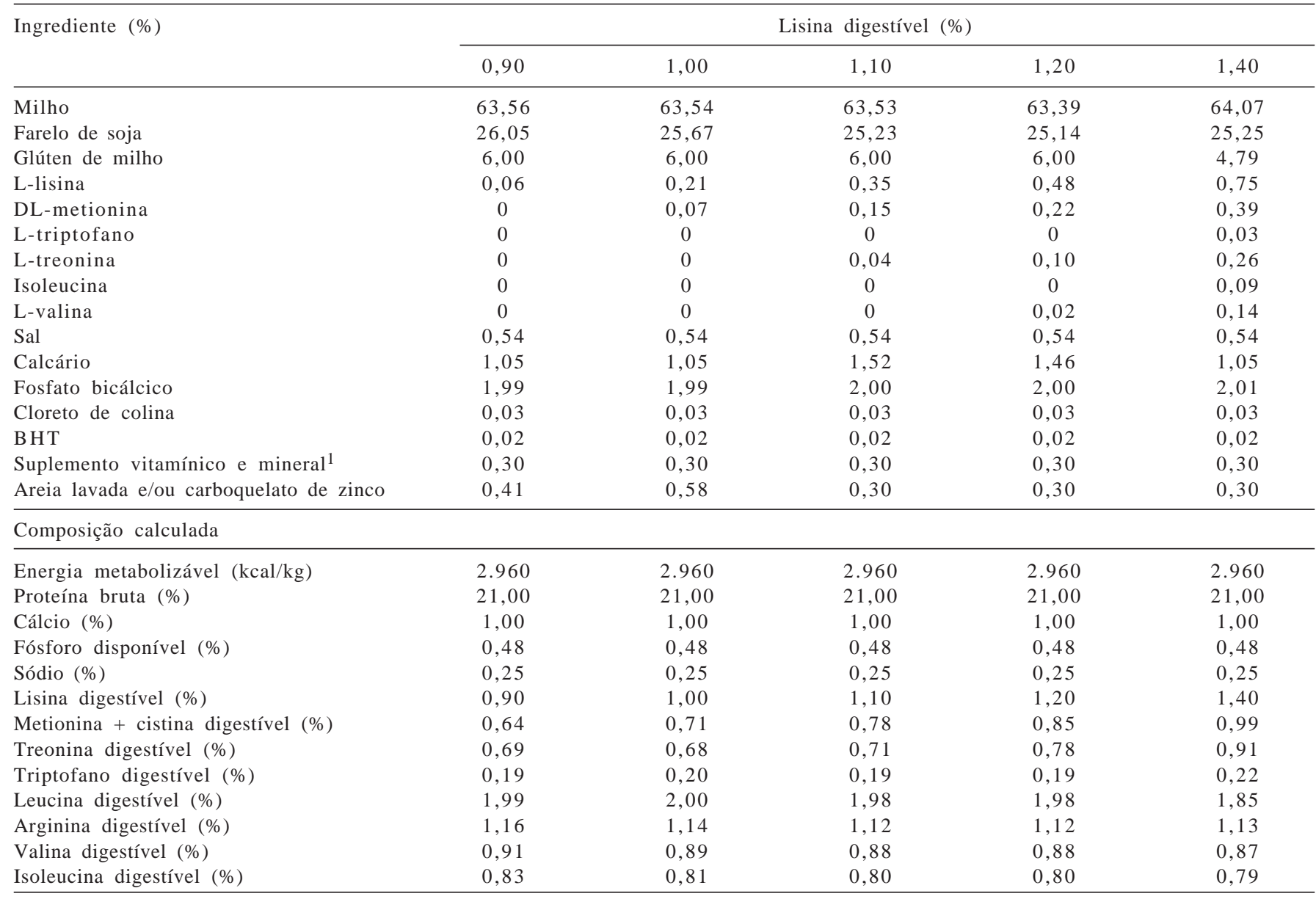

${ }^{1}$ Conteúdo/kg de produto: Mn - 18.662 ppm; Fe - 14.479 ppm; Zn - 14.452 ppm; Cu - 2.855 ppm; I - 187 ppm; Se - 113 ppm; vit. A - 3.525 .000 UI; vit. D 3 851.250 UI; vit. E - 4.959 ppm; vit. $\mathrm{K}_{3}-600$ ppm; vit. $\mathrm{B}_{1}-670$ ppm; vit. $\mathrm{B}_{2}$ - 1.500 ppm; vit. $\mathrm{B}_{6}$ - 830 ppm; vit. $\mathrm{B}_{12}-4$ ppm; niacina - 10.000 ppm; ácido pantotênico - 3.915 ppm; ácido fólico - 250 ppm; biotina - 33 ppm; antioxidante - 1.400 ppm.

fatorial $5 \times 2$, composto pelos fatores principais lisina digestível ( 0,$90 ; 1,00 ; 1,10 ; 1,20 ;$ e 1,40\%) e zinco quelado (43 ppm e 253 ppm na forma de carboquelato) na ração. O experimento 1 foi formado de sete repetições e o experimento 2, de seis repetições. A unidade experimental foi constituída de 15 e 6 aves, respectivamente.

As dietas experimentais definitivas foram calculadas após análise bromatológica completa dos ingredientes. As dietas experimentais (Tabela 1), isoprotéicas e isoenergéticas, foram elaboradas segundo recomendações de Rostagno et al. (2005). As rações foram fornecidas à vontade, em quantidades estabelecidas no manual da linhagem (Agroceres, 2004) para o período de 1 a 11 dias de idade para avaliação do desempenho e para o período de 1 aos 7 dias para avaliação do balanço de nitrogênio.

Os valores de aminoácidos totais foram corrigidos para valores digestíveis (Tabela 2) aplicando-se o índice 87,72\% para corrigir os valores estimados de lisina pelas equações de regressão. Esse fator de correção $(0,8772)$ foi obtido com base na média ponderal dos coeficientes de digestibilidade indicados por Rostagno et al. (2005) para lisina total, conforme os níveis de milho, farelo de soja e glúten nas dietas experimentais.

As análises estatísticas das variáveis estudadas foram realizadas utilizando-se o procedimento GLM do programa computacional Statistical Analysis System (1999) e a regressão para níveis de lisina.

\section{Resultados e Discussão}

Os valores médios das temperaturas aferidos no primeiro ensaio foram $25^{\circ} \mathrm{C}$ (máxima) e $18,5^{\circ} \mathrm{C}$ (mínima). Os índices pluviométricos e de umidade relativa do ar mantiveram-se dentro dos padrões estimados para a região.

Não houve interação de lisina digestível e zinco para as características de desempenho avaliadas (Tabela 3), apesar dos relatos na literatura sobre uso do zinco na forma de quelato e suas ações locais no trato digestório. Os resultados obtidos neste estudo diferem dos relatados por Hudson et al. (2005), que observaram que a suplementação dietética 
Tabela 2 - Análises de aminoácidos totais das dietas experimentais $(\%)^{1}$

\begin{tabular}{lccccc}
\hline & \multicolumn{5}{c}{ Lisina } \\
\hline Lisina calculada & 0,90 & 1,00 & 1,10 & 1,20 & 1,40 \\
\hline Matéria seca & 93,39 & 94,90 & 93,04 & 94,84 & 92,77 \\
Proteína bruta & 25,18 & 24,30 & 23,47 & 24,95 & 23,67 \\
Lisina total & 1,13 & 1,18 & 1,27 & 1,39 & 1,57 \\
Lisina digestível ${ }^{2}$ & 0,99 & 1,03 & 1,11 & 1,21 & 1,37 \\
Treonina & 0,80 & 0,84 & 0,87 & 0,94 & 1,04 \\
Metionina & 0,38 & 0,42 & 0,47 & 0,52 & 0,67 \\
Cistina & 0,34 & 0,33 & 0,32 & 0,34 & 0,34 \\
Metionina + cistina & 0,72 & 0,75 & 0,80 & 0,86 & 1,01 \\
Alanina & 1,50 & 1,41 & 1,40 & 1,44 & 1,31 \\
Arginina & 1,39 & 1,32 & 1,33 & 1,43 & 1,53 \\
Ácido aspártico & 2,20 & 2,07 & 2,05 & 2,11 & 2,10 \\
Ácido glutâmico & 4,39 & 4,17 & 4,17 & 4,17 & 4,27 \\
Glicina & 0,95 & 0,90 & 0,90 & 0,92 & 0,88 \\
Histidina & 0,61 & 0,58 & 0,58 & 0,59 & 0,58 \\
Isoleucina & 1,00 & 0,95 & 0,94 & 0,96 & 1,00 \\
Leucina & 2,60 & 2,46 & 2,44 & 2,49 & 2,27 \\
Fenilalanina & 1,28 & 1,23 & 1,21 & 1,24 & 1,17 \\
Serina & 1,25 & 1,17 & 1,17 & 1,20 & 1,10 \\
Tirosina & 0,88 & 0,87 & 0,84 & 0,86 & 0,84 \\
Valina & 1,14 & 1,08 & 1,07 & 1,12 & 1,17 \\
\hline
\end{tabular}

${ }^{1}$ Análises realizadas pela empresa Ajinomoto Biolatina Ind. e Com. Ltda. 2 Valor estimado.

de zinco combinado a aminoácido (ZnAA) para frangos de corte favoreceu o crescimento e a conversão alimentar das aves no intervalo de 0 a 17 dias de idade. Esses autores destacaram ainda que, em níveis mais baixos desse mineral, a absorção do aminoácido seria melhorada.

A suplementação com 43 e 253 ppm de zinco quelado não promoveu diferenças nas características de desempenho. O aumento da concentração de lisina, no entanto, coincidiu com a variação $(\mathrm{P}<0,01)$ quadrática do ganho de peso e com o aumento $(\mathrm{P}<0,01)$ linear do consumo de ração (Tabelas 3 e 4). Nesses mesmos períodos, a eficiência de utilização dos aminoácidos se associa ao aumento de massa muscular e/ou à retenção de nitrogênio. Essa nutrição protéica é fundamental no desempenho de frangos de corte e a lisina se torna referência entre os demais aminoácidos.

Nas características de desempenho avaliadas, o nível estimado de lisina digestível como ótimo corresponde a 1,19\%, segundo equação de regressão (Tabela 4). Considerando o índice de digestibilidade de 0,8772 para o valor de lisina total analisado, o nível digestível do aminoácido seria de 1,219\%.

O nível de 1,19\% observado (Tabela 4) foi inferior ao encontrado por Toledo (2003), que estudou a influência dos níveis de lisina digestível e do efeito ambiente, sem infecção e com cama reutilizada, sobre o desempenho de pintinhos de corte de 1 a 11 dias de idade e recomendaram nível de lisina digestível de 1,30 e 1,26\% para os respectivos ambientes. Ressalta-se, porém, que Butteri (2001) sugeriu para frangos de corte machos no período de 1 a 14 dias de idade $1,247 \%$ de lisina digestível para maior desempenho.

Estudos com pintos de corte Ross machos no período de 1 a 11 dias de idade, citados em Ajinomoto (2005), indicam que o nível de lisina digestível utilizado para a fase não deve ser inferior a $1,20 \%$ quando as aves são criadas sob baixo desafio imunológico. Nesses estudos, os níveis indicados são superiores ao recomendado por Toledo (2002), de 1,18\% para aves na mesma fase de criação (1 a 11 dias). Kidd \& Fancher (2001) avaliaram níveis de lisina na fase inicial (1 a 18 dias) e seus efeitos no período de crescimento e recomendaram $1,22 \%$ de lisina total para máximo crescimento e qualidade de carcaça.

Knowles \& Southern (1998), com base no ganho de peso, recomendaram para frangos de corte machos no período de 4 a 15 dias de idade 1,09\% de lisina digestível. Toledo et al. (2007), no entanto, concluíram que o nível máximo de lisina digestível é de 1,12\% para frangos de corte no período de 1 a 11 dias de idade e sugeriram estudos para avaliação de níveis mais baixos.

No período de avaliação, constatou-se aumento $(\mathrm{P}<0,05)$ linear do consumo diário de ração pelas aves de acordo com a concentração de lisina na dieta, resultado que difere das respostas para ganho de peso, cuja resposta foi quadrática. Revisando estudos com frangos de corte, Figueiredo \& Amara (2005) observaram que aos 2 dias de idade o pintinho consome aproximadamente $10 \mathrm{~g}$ de ração por dia e aos 7 dias esse consumo aumenta para 35 g. Neste estudo as aves consumiram em torno de $38 \mathrm{~g}$ aos 7 dias de vida.

Em caso de excessiva ingestão e absorção de aminoácidos, o excedente é eliminado na forma de ácido úrico, o que implica custo energético adicional para a ave (Sklan \& Noy, 2004) e tem efeitos negativos no consumo de alimento. Entretanto, em níveis satisfatórios ao metabolismo, a ave pode apresentar maior desempenho e/ou eficiência alimentar. Conhalato et al. (1999), utilizando frangos de corte machos na fase inicial de crescimento, concluíram que o nível 1,05\% de lisina digestível aumentou o ganho de peso e o de 1,03\% melhorou a conversão alimentar.

Segundo orientações contidas no manual técnico da empresa genética para a linhagem, o nível de lisina digestível recomendado é de $1,10 \%$ no período de 1 a 10 dias de idade. Esse nível, no entanto, estaria abaixo do obtido neste estudo, de 1,19\%.

No ensaio de digestibilidade, os valores médios das temperaturas obtidas durante o período experimental foram $27,5^{\circ} \mathrm{C}$ (máxima) e $24,5^{\circ} \mathrm{C}$ (mínima). Os índices pluviométricos e de umidade relativa do ar mantiveram-se nos padrões estimados para a região. 
Tabela 3 - Desempenho de frangos de corte de 1 a 11 dias de idade alimentados com rações contendo lisina digestível e zinco quelado

\begin{tabular}{|c|c|c|c|c|c|c|c|c|c|c|c|}
\hline \multirow[t]{2}{*}{ Característica } & \multicolumn{5}{|c|}{ Lisina digestível (\%) } & \multicolumn{2}{|c|}{ Zinco quelado } & \multirow[t]{2}{*}{ Média } & \multirow[t]{2}{*}{ CV \% } & \multirow[t]{2}{*}{$\mathrm{L}^{*}$} & \multirow[t]{2}{*}{$\mathrm{Q}^{*} \mathrm{~s}$} \\
\hline & 0,90 & 1,00 & 1,10 & 1,20 & 1,40 & 43 ppm & $253 \mathrm{ppm}$ & & & & \\
\hline Peso médio final (g) & 248 & 291 & 300 & 318 & 314 & $291 \mathrm{a}$ & $296 a$ & 294 & 5,27 & ns & $\mathrm{P}<0,01$ \\
\hline Ganho de peso médio (g) & 202 & 246 & 254 & 272 & 268 & $246 a$ & $251 \mathrm{a}$ & 248 & 6,25 & ns & $\mathrm{P}<0,01$ \\
\hline Ganho de peso relativo (g) & 447 & 542 & 562 & 599 & 589 & $552 a$ & $543 a$ & 548 & 6,68 & ns & $\mathrm{P}<0,01$ \\
\hline Consumo de ração médio (g) & 241 & 273 & 258 & 291 & 279 & $265 a$ & $272 \mathrm{a}$ & 268 & 15,27 & $\mathrm{P}<0,01$ & ns \\
\hline Conversão alimentar & 1,01 & 0,95 & 0,86 & 0,92 & 0,90 & $0,91 \mathrm{a}$ & $0,94 \mathrm{a}$ & 0,93 & 17,64 & ns & ns \\
\hline $\begin{array}{l}\text { Lisina:energia metabolizável } \\
(\% / \text { Mcal })^{1}\end{array}$ & 0,3 & 0,33 & 0,37 & 0,4 & 0,47 & $0,37 a$ & $0,37 \mathrm{a}$ & 0,37 & nd & nd & nd \\
\hline Ingestão de lisina $(\mathrm{g})^{1}$ & 2,10 & 2,70 & 2,80 & 3,40 & 4,00 & $2,60 \mathrm{a}$ & $2,70 \mathrm{a}$ & 2,90 & nd & nd & nd \\
\hline $\begin{array}{l}\text { Ingestão de lisina } \\
(2,96 \text { Mcal de } \mathrm{ME})^{1}\end{array}$ & 0,71 & 0,91 & 0,94 & 1,14 & 1,35 & $0,88 \mathrm{a}$ & $0,91 \mathrm{a}$ & 0,98 & nd & nd & nd \\
\hline
\end{tabular}

1 Valor estimado com base na composição calculada.

nd: não-determinado; ns: não-significativo $(P>0,10)$; L - linear, Q - quadrático.

Médias seguidas de mesma letra na mesma linha não diferem entre si pelo teste $\mathrm{F}$.

Tabela 4 - Equações das características de desempenho, considerando o percentual de lisina digestível calculado em dietas para frangos de corte de 1 a 11 dias de idade ${ }^{1}$

\begin{tabular}{lcc}
\hline Característica & Equação & $\mathrm{R}^{2}$ \\
\hline Peso médio final (g) & $\hat{\mathrm{Y}}=-481,3499+1256,7002 \mathrm{X}-492,3220 \mathrm{X}^{2}$ & 0,96 \\
Ganho em peso médio (g) & $\hat{\mathrm{Y}}=-525,1640+1254,3837 \mathrm{X}-491,5709 \mathrm{X}^{2}$ & 0,96 \\
Ganho em peso relativo (g) & $\hat{\mathrm{Y}}=-1152,1536+2760,0576 \mathrm{X}-1083,5554 \mathrm{X}^{2}$ & 0,96 \\
Consumo de ração médio (g) & $\hat{\mathrm{Y}}=188,6941+71,2577 \mathrm{X}$ & 0,49 \\
\hline
\end{tabular}

${ }^{1}$ Nível de significância $(P<0,01)$.

Não ficou caracterizada interação lisina digestível $\times$ zinco quelado para o metabolismo (Tabela 5), mas houve efeito linear $(\mathrm{P}<0,01)$ crescente $(\hat{\mathrm{Y}}=51,99+49,2871640 \mathrm{X}$; $\left.\mathrm{R}^{2}=0,61\right)$ sobre o ganho de peso individual no período de 1 a 7 dias de idade. Os valores médios de ganho de peso obtidos nos níveis de lisina digestível foram: 88,3; 113,7; 113,2; 112,3 e 121,7 g, enquanto para zinco foram: 109 e $110,73 \mathrm{~g}$, respectivamente.

O melhor desempenho quando fornecidos níveis crescentes de lisina digestível sugere nível não inferior a 1,40\% desse aminoácido digestível. Esse nível é maior que o de $1,36 \%$ recomendado por Rostagno et al. (2005), todavia, se considerado o baixo coeficiente de determinação, essa variável não estaria, satisfatoriamente, determinada.

Os resultados de desempenho no perído de 1 a 7 dias indicam que o aumento de aminoácidos não afetou o consumo de alimento e a conversão alimentar das aves. Em situação contrária, o excesso de consumo de aminoácidos normalmente sobrecarrega as atividades hepáticas e renais nos processos associados à desaminação (Toledo et al., 2007) para eliminação do nitrogênio.

A ingestão de MS não foi influenciada pelo nível dietético de lisina, não obstante, a maior concentração do zinco quelado indica $(\mathrm{P}=0,08)$ benefício da inclusão do mineral na forma orgânica.
Verificou-se aumento linear $(\mathrm{P}<0,01)$ na ingestão de proteína bruta e nitrogênio ingerido (g) com o aumento do nível de lisina digestível na dieta, resultado esperado, se consideradas as características nesse fator.

Em aves recém-nascidas, a rápida ingestão de alimento favorece a adaptação e a digestão e absorção dos nutrientes, uma vez que ocorre aumento gradativo das atividades enzimáticas. O consumo de ração em aves durante a fase pré-inicial pode estar relacionado à capacidade de digestão da dieta. Esse consumo não deve exceder a capacidade digestiva (Noy \& Sklan, 1995).

A fração endógena de nitrogênio intestinal logo após a eclosão é pequena, mas aumenta com a idade e a ingestão de alimento (Noy \& Sklan, 1998, 2000).

Houve resposta linear $(\mathrm{P}=0,05)$ favorável à retenção de nitrogênio à medida que aumentou a ingestão de lisina digestível, o que caracteriza eficiência de uso do nitrogênio. Sabe-se que os aminoácidos são utilizados pelas aves para manutenção da saúde e integridade dos tecidos e, posteriormente, para produção de músculos, ovos, pele, penas e tudo que contenha proteína (Barbosa et al., 2002). O aumento na retenção de nitrogênio neste estudo estaria associado à priorização do nutriente para o crescimento da ave.

Os pintinhos de corte na primeira semana de vida apresentam capacidade limitada de digestão protéica, em 
Tabela 5 - Digestibilidade e metabolismo em frangos de corte de 5 a 7 dias de idade alimentados com rações contendo lisina digestível e zinco quelado

\begin{tabular}{|c|c|c|c|c|c|c|c|c|c|c|c|}
\hline \multirow[t]{2}{*}{ Característica } & \multicolumn{5}{|c|}{ Lisina digestível (\%) } & \multicolumn{2}{|c|}{ Zinco quelado } & \multirow[t]{2}{*}{ Média } & \multirow[t]{2}{*}{ CV \% } & \multirow[t]{2}{*}{$\mathrm{L}^{*}$} & \multirow[t]{2}{*}{$\mathrm{Q}^{*}$} \\
\hline & 0,90 & 1,00 & 1,10 & 1,20 & 1,40 & 43 ppm & $253 \mathrm{ppm}$ & & & & \\
\hline Matéria seca ingerida/ave & 90,2 & 107,5 & 103,0 & 102,1 & 113,6 & $100,9 b$ & $105,6 a$ & 103,3 & 10,31 & ns & ns \\
\hline Matéria seca excretada/ave (\%) & 13,2 & 16,3 & 16,0 & 15,6 & 16,8 & $16,4 \mathrm{a}$ & $17,2 \mathrm{a}$ & 15,6 & 7,36 & ns & ns \\
\hline Proteína bruta ingerida/ave (\%) & 21,02 & 24,97 & 25,09 & 24,14 & 27,64 & $24,23 a$ & $24,91 \mathrm{a}$ & 24,57 & 10,34 & $\mathrm{P}<0,01$ & ns \\
\hline Matéria seca digestível (\%) & 85,30 & 84,68 & 84,96 & 84,94 & 85,13 & $85,00 \mathrm{~b}$ & $85,25 a$ & 85,00 & 1,49 & ns & ns \\
\hline Nitrogênio ingerido (\%) & 7,47 & 8,88 & 8,90 & 8,64 & 9,81 & $8,85 \mathrm{a}$ & 8,63a & 8,74 & 13,01 & $\mathrm{P}<0,01$ & ns \\
\hline Nitrogênio retido (\%) & 77,31 & 77,51 & 79,53 & 78,69 & 79,29 & $78,13 a$ & $78,80 a$ & 77,96 & 3,46 & $P=0,05$ & ns \\
\hline Energia metabolizável (kcal) & 3.374 & 3.320 & 3.318 & 3.338 & 3.345 & 3323b & $3.354 a$ & 3.339 & 1,58 & ns & ns \\
\hline EM:EB (kcal) & 86 & 85 & 86 & 86 & 86 & $86 a$ & $85 a$ & 86 & 1,59 & ns & ns \\
\hline Energia bruta ingerida/ave (kcal) & 118 & 140 & 133 & 133 & 148 & $130 \mathrm{~b}$ & $137 \mathrm{a}$ & 134 & 10,3 & ns & ns \\
\hline Energia bruta excretada/ave (kcal) & 16 & 20 & 20 & 20 & 21 & $20 \mathrm{a}$ & $19 a$ & 19 & 7,64 & ns & ns \\
\hline $\begin{array}{l}\text { Balanço energia } \\
\text { metabolizável (kcal) }\end{array}$ & 101 & 119 & 118 & 113 & 127 & $113 a$ & $118 \mathrm{a}$ & 116 & 11,26 & ns & ns \\
\hline
\end{tabular}

1 Desempenho de frangos de corte de 1 aos 7 dias de idade.

$L^{*}$-linear $Q^{*}$-quadrático somente para efeito de lisina digestível; ns: não-significativo.

Médias seguidas de letras diferentes no fator zinco quelado na mesma linha diferem $(P<0,05)$ entre si pelo teste $F$.

razão do lento desenvolvimento do trato digestório (Penz Jr. \& Vieira, 1998) e da baixa atividade enzimática de tripsina (Noy \& Sklan, 1995). Neste estudo, os resultados de digestibilidade do nitrogênio foram próximos aos descritos por Noy \& Sklan (1995) de que na primeira semana a proteólise não é suficiente para liberar integralmente os pequenos peptídeos e aminoácidos das proteínas exógenas fornecidas via ração. Desse modo, a excreção fecal de nitrogênio tende a aumentar de forma linear e resulta em baixa digestibilidade da proteína.

A presença de zinco orgânico em maior concentração indica $(\mathrm{P}=0,06)$ melhor resposta para a energia ingerida para mantença da imunidade da ave, porém, mais estudos são suscitados para se estabelecer mais informações sobre o assunto. A proteína bruta ingerida, como ocorreu com nitrogênio, teve aumento linear ascendente ( $\hat{Y}=12,870494$ $\left.+10,4504524 \mathrm{X} ; \mathrm{R}^{2}=0,71\right)$ de acordo com aumento do nível de lisina digestível na dieta. O menor consumo foi observado nas aves que receberam dieta de menor nível de lisina digestível. A retenção linear indica necessidade dietética igual ou maior que $1,40 \%$ do aminoácido, pois a capacidade de crescimento (síntese protéica) é superior às necessidades de consumo. O coeficiente de determinação para a variável deveria ser, no entanto, mais representativo quando a ave é mais exposta às adversidades do ambiente e manejo, como a criação em galpão compacto sobre cama.

\section{Conclusões}

Não houve relação de dependência entre os níveis de lisina digestível e zinco quelado utilizados na dieta. Em criação de piso de concreto, o nível ótimo de lisina digestível para frangos de corte machos de 1 aos 11 dias de idade é de
1,19\%. A utilização da energia dietética melhora com o fornecimento de zinco quelado na dieta.

\section{Literatura Citada}

AGRoCERES. [2004]. Manual de manejo de frangos AGRoss. Disponível em: <http://www.agroceresross.com.br/servlet/ navSrvt?cmd=listPublicacaoFrango\&id=47.> Acesso em: 14/1/2004.

AJINOMOTO BIOLATINA. [2005]. Lisina: principal aminoácido para deposição protéica. Disponível em: http://www.lisina. com.br. Acesso em: 19/5/2006.

AOYAGI, S.; BAKER, D.H. Nutritional evaluation of a cooperlysine and zinc-lysine complexes for chicks. Poultry Science, v.72, n.1, p.16-171, 1993.

AZCONA, J.; SCHANG, M.; CORTAMIRA, O. [2003]. Nível de lisina nas rações de frangos de corte: Experimento $1-22$ a 42 dias de idade, Experimento 2 - 36 a 49 dias de idade. Disponível em: http://<www.lisina.com.br> Acesso em: 21/3/2006.

BAKER, D.H.; HAN, Y. Ideal amino acid profile for chicks during the first three weeks posthatching. Poultry Science, v.73, p.1441-1447, 1994.

BARBOSA, M.J.P.; JUNQUEIRA, O.M.; ANDREOTTI, M.O. et al. Níveis de lisina + metionina para frangos de corte na fase inicial. Acta Scientarium v.24, n.4, p.1007-1013, 2002.

BUTTERI, C.B. Níveis nutricionais de lisina digestível no desempenho produtivo e econômico de frangos de corte. Viçosa, MG: Universidade Federal de Viçosa, 2001. 58p. Dissertação (Mestrado em Zootecnia) - Universidade Federal de Viçosa, 2001.

CHENG, J.; KORNEGAY, E.T.; SCHELL, T. Influence of dietary lysine on the utilization of zinc from zinc sulfate and a zinclysine complex by young pigs. Journal of Animal Science, v.76, p.1064-1074, 1998.

HUDSON, B.P.; DOZIER III, W.A.; WILSON, J.L. Broiler live performance response to dietary zinc source and the influence of zinc supplementation in broiler breeder diets. Animal Feed Science and Technology, v.118, n.3-4, p.329-335, 2005.

CONHALATO, G.S.; DONZELE, J.L.; ROSTAGNO, H.S. níveis de lisina digestível para pintos de corte machos na fase de 1 a 21 dias de idade. Revista Brasileira de Zootecnia, v.28, p.91-97, 1999.

FALLAVENA, L.C.B. Enfermidade da pele e das penas. In: BERCHIERI JR., A.; MACARI, M.M. (Eds.). Doença das aves. Campinas: Fundação Apinco de Ciência e Tecnologia Avícolas, 2000. p.37-45. 
FARRELL, D.J. Metabolizable energy em feeding systems for pigs and poultry. Proceedings Australian Society Animal Production, v.12, p.62-67, 1978.

FERREIRA, W.M.; CAVALCANTE, S.G.; NARANJO, A.P. et al. Biodisponibilidade de diferentes fontes de zinco para coelhos. Arquivo Brasileiro Medicina Veterinária e Zootecnia, v.54, n.6, p.618-622, 2002.

FIGUEIREDO, C.H.R.; AMARA, R. Importância e beneficios da dieta pré-inicial diferenciada para pintinhos na primeira semana. In: SIMPÓSIO GOIANO DE AVICULTURA, 7.; SIMPÓSIO GOIANO DE SUINOCULTURA-AVESUI- CENTRO-OESTE, 2.; SEMINÁRIOS TÉCNICOS DE AVICULTURA, 1., 2005, Goiânia. Anais... Goiânia: 2005. p.243.

KIDD, M.T. Lysine and threonine needs of commercial broilers. Ajinomoto heartland. In: POULTRY SYMPOSIUM, 2001, Nashville. Proceedings... Nashville: 2001. p.128.

KIDD, M.T.; KERR, B.J. Threonine in the poultry nutrition. In: MEETING ARKANSAS NUTRITION CONFERENCE, 1996, Arkansas. Proceedings... Arkansas: 1996, p.203-228.

KIDD, M.; FANCHER, B.I. Lysine needs of starting chicks and subsequent effect during the growing period. Journal of Applied Poultry Research, v.10, p.385-393, 2001.

KNOWLES, T.A.; SOUTHERN, L.L. The lysine requirement and ratio of total sulfur amino acids to lysine for chicks fed adequate or inadequate lysine. Poultry Science, v.77, p.564-569, 1998.

LEE, S.H.; CHOI, S.C; CHAE, B.J. et al. Evaluation of metalamino chelates and complexes at various levels of copper and zinc in weanling pigs and broiler chicks. Asian-Australian Journal of Animal Science, v.14, p.1734-1740, 2001.

NOY, Y.; SKLAN, D. Digestion and absorption in young chick. Poultry Science, v.74, p.366-373, 1995.

NOY, Y.; SKLAN, D. Metabolic responses to early nutrition. Journal Applied Poultry Research, v.7, p.437-451, 1998.
NOY, Y.; SKLAN, D. Decreasing weight loss in the hatchery by feeding chickens and poults in hatching trays. Journal Applied Poultry Research, v.9, p.142-148, 2000.

PENZ JR., A.M.; VIEIRA, S.L. Nutrição na primeira semana. In: SIMPÓSIO INTERNACIONAL SOBRE MANEJO DE PINTO DE CORTE NA PRIMEIRA SEMANA, Campinas, 1998. Anais... Campinas: Fundação Apinco de Ciência e Tecnologia Avícolas, 1998. p.121-139.

Rostagno, H.S.; ALBINO, L.F.T.; DOnZELE, J.L. Tabelas brasileiras para aves e suínos: composição de alimentos e exigências nutricionais. Viçosa, MG: Universidade Federal de Viçosa, 2005. 186p.

STATISTICAL ANALISYS SYSTEM - SAS. SAS user's guide: statistics. Versão 5. Cary: SAS Institute, 1999. (CD-ROM).

SKLAN, D.; NOY, Y. Catabolism and deposition of aminoacids in growing chicks: effect of dietary suply. Poultry Science, v.83, p.952-961, 2004.

SPEARS, J.W.; SCHOENHERR, W.D.; KEGLEY, E.B. et al. Efficacy of iron methionine as a source of iron for nursing pigs. Journal of Animal Science, v.70, p.243, 1992. (suppl. 1).

TOLEDO, A.L.; TAKEARA, P.; KOBASHIGAWA, E. et al. Níveis dietéticos de lisina digestível para frangos de corte machos no período de 1 a 11 dias de idade: desempenho e composição corporal. Revista Brasileira de Zootecnia, v.36, n.4, p.10901096, 2007 (supl.)

TOLEDO, R.S. Exigência nutricional de lisina e de proteína bruta para frangos de corte criados em ambiente limpo e sujo. Viçosa, MG: Universidade Federal de Viçosa, 2003. 103p. Tese (Doutorado em Zootecnia) - Universidade Federal de Viçosa, 2003.

TOLEDO, R.S. Níveis nutricionais e forma física da ração préinicial para frangos de corte. Viçosa, MG: Universidade Federal de Viçosa, 2002. 47p. Tese (Doutorado em Zootecnia) Universidade Federal de Viçosa, 2002. 